Journal of

Molecular Microbiology and Biotechnology

Bell, S.D. 420

Chattoraj, D.K. 360

Cornet, F. 396

Crémazy, F. 344

Crozat, E. 396

Dame, R.T. 344

Dorman, C.J. 316

Fournes, F. 396

Graumann, P.L. 291, 384

Herrera, V. 371
Jha, J. 360

Kleine Borgmann, L.A.K. 384

Messerschmidt, S.J. 301

Muskhelishvili, G. 332

Petrushenko, Z.M. 371

Ramachandran, R. 360

Rousseau, P. 396

Rybenkov, V.V. 371

Samson, R.Y. 420

Soppa, J. 409
Travers, A. 332

van der Valk, R.A. 344

Vreede, J. 344

Waldminghaus, T. 301

Zhao, H. 371

\title{
Subject Index Vol. 24, No. 5-6, 2014
}

Archaea 409, 420

Archaeal chromatin 344

Bacteria 409

Bacterial cell cycle 384

- chromatin 344

- chromosome 371

- mitosis 360

Biological order 332

Chromosome condensation 384

- dimers 396

- replication 420

- scaffold 371

- segregation 301, 384, 396

- structure 316,371

Condensin(s) 371

Coordination of replication and segregation 360
Divided genomes 360

DNA code 332

- looping 344

- replication 301

- supercoiling 332

- translocase(s) 384, 396

- transport 396

Eukaryotes 420

FtsK 396

Genetic system 332

H-NS protein 344

Holistic methodology 332

Initiator proteins 420
Macrodomains 301

Microdomains 301

MksB 371

MukB 371

Nucleoid 344

Nucleoid-associated protein 316

Par-independent polar segregation 360 Polyploidy 409

Pseudomonas aeruginosa 371

SpoIIIE 396

Structural maintenance of chromosomes (SMC) 384

Topoisomerase 316,332

Transcription 316

\section{KARGER}

(C) 2015 S. Karger AG, Basel 